\title{
Lineage-specific chimerism analysis in nucleated cells, T cells and natural killer cells after myeloablative allogeneic hematopoietic stem cell transplantation
}

\author{
Ri-Young Goh ${ }^{1}$, Sung-Hyun Kim², Jin-Yeong $\operatorname{Han}^{1}$ \\ Departments of ${ }^{1}$ Laboratory Medicine, ${ }^{2}$ Internal Medicine, Dong-A University College of Medicine, Busan, Korea
}

p-ISSN 1738-7949 / e-ISSN 2092-9129

DOI: $10.5045 / \mathrm{kjh} .2011 .46 .1 .18$

Korean J Hematol 2011;46:18-23.

Received on February 24, 2010

Revised on February 8, 2011

Accepted on February 8, 2011
*This study was supported by a grant of the Korea Health 21 R\&D Project, Ministry of Health \& Welfare, Republic of Korea (A050099).

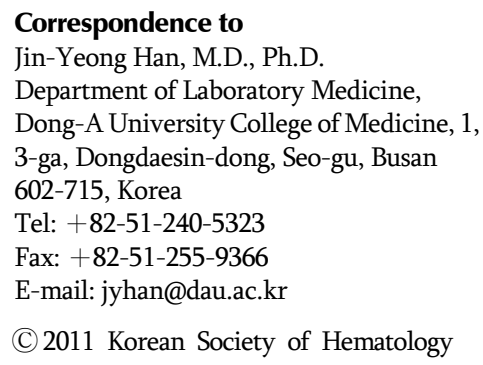

\begin{abstract}
Background
Chimerism analysis is an important tool for assessing the origin of hematopoietic cells after allogeneic stem cell transplantation (allo-SCT) and can be used to detect impending graft rejection and the recurrence of underlying malignant or nonmalignant diseases.
\end{abstract}

\section{Methods}

This study included 24 patients who underwent myeloablative allo-SCT. DNA was extracted from nucleated cells (NCs), T cells, and natural killer (NK) cells, and the chimerism status of these cell fractions was determined by STR-PCR performed using an automated fluorescent DNA analyzer.

\section{Results}

Twenty-three out of the 24 patients achieved engraftment. Mixed chimerism (MC) in NCs, but not in T cells and NK cells, was significantly correlated with disease relapse. MC in all cell fractions was correlated with mortality. Ten patients (41.6\%) developed extensive chronic GVHD. Six patients had MC in T cells, and 3 of them had chronic GVHD. Four patients with MC and relapse received donor lymphocyte infusion (DLI), and among them, 3 had secondary relapse. Further, the chimerism status differed among different cell lineages in 6 patients with myeloid malignancies.

\section{Conclusion}

The implications of MC in lymphocyte subsets are an important area for future research. Chimerism analysis in lineage-specific cells permits detection of relapse and facilitates the monitoring of therapeutic interventions. These results can provide the basic data for chimerism analysis after myeloablative SCT.

Key Words Lineage-specific chimerism, Myeloablative stem cell transplantation, $\mathrm{T}$ cells, Natural killer cells

\section{INTRODUCTION}

Chimerism analysis is an important tool used to assess the origin of hematopoietic cells after allogeneic stem cell transplantation (allo-SCT). After allo-SCT, both donor and recipient hematopoietic cells can coexist in the recipient, and this state is called mixed chimerism (MC). In patients with $\mathrm{MC}$, the percentage of recipient cells could remain stable, increase, or spontaneously decrease over time [1-8]. The presence of recipient cells in the peripheral blood (PB) or bone marrow (BM) of patients during the posttransplant period is an important prognostic indicator of transplant rejection, disease relapse, and graft-versus-host disease (GVHD) [9-12].

Several methods have been developed to assess the level of donor engraftment after allo-SCT. Fluorescent in situ hybridization of sex chromosomes (XY-FISH) and PCR-based analysis of polymorphic DNA sequences are the most widely used techniques, and real-time PCR techniques based on analysis of the Y chromosome or on single nucleotide polymorphisms (SNPs) are being evaluated. Currently, fluorescence-based PCR amplification of short tandem repeats (STRs) is the gold standard for analyzing post-transplant chimerism and has been used in most studies [13-15].

$\mathrm{PB}$ or $\mathrm{BM}$ is most often used for chimerism analysis, with

This is an Open Access article distributed under the terms of the Creative Commons Attribution Non-Commercial License (http://creativecommons.org/licenses/by-nc/3.0) which permits unrestricted non-commercial use, distribution, and reproduction in any medium, provided the original work is properly cited. 
or without further manipulation of different cell subpopulations. It is important to realize that patients could show complete chimerism (CC) in one cell type, for example, T cells, whereas others could be totally or in part recipient-derived. This is called split chimerism $[3,8]$.

Many studies have investigated nonmyeloablative conditioning regimens for split chimerism. We compared donor-recipient chimerism levels in nucleated cells (NCs) and lineage-specific cell subtypes, namely, $\mathrm{T}$ cells and natural killer (NK) cells, after myeloablative allo-SCT by using multiplex STR-PCR in order to determine the sensitivity and specificity for the detection of minimal residual disease. Moreover, we analyzed the correlation between chimerism status and clinical outcome, including cumulative incidence of GVHD and relapse. There have been few studies in Korea about chimerism or discrepant results among various cell lineages.

\section{MATERIALS AND METHODS}

\section{Patients and specimens}

This study included 24 patients who underwent allo-SCT between December 2001 and September 2008 in our in- stitution; patient characteristics are shown in Table 1. Ethylenediaminetetraacetic acid (EDTA)-treated PB samples were obtained from both the donor and recipient before transplantation. After allo-SCT, recipient PB samples were drawn every month for the first 3 months and then every 3 months for 2 years or until the recipient's death. NCs were isolated by density gradient centrifugation by using Ficoll-Paque ( $\mathrm{d}=1.077 \mathrm{~g} / \mathrm{mL}$; Pharmacia, Sweden). T cells $\left(\mathrm{CD} 3^{+}\right)$and NK cells $\left(\mathrm{CD}^{+} 6^{+}\right)$cells were separated using the RosetteSep antibody cocktail (Stem Cell Technologies; Vancouver, BC, Canada) according to the manufacturer's instructions, with minor modifications. Genomic DNA was extracted from NCs and from $\mathrm{CD}^{+}$and $\mathrm{CD}^{+} 6^{+}$cells by using the QIAamp Blood Kit (Qiagen; Chatsworth, CA, USA).

\section{Chimerism analysis}

Chimerism studies were performed using the AmpF/STR Identifiler PCR Amplification Kit (Applied Biosystems; Norwalk, CT, USA), which simultaneously amplifies 15 STR loci and the gender-determination marker Amelogenin. The PCR products were analyzed using ABI 3100 Genetic Analyzer (Applied Biosystems). Fluorescence was quantified, and the precise size of the DNA fragments was calculated with the Genotyper software (Applied Biosystems). The per-

Table 1. Patient characteristics and their clinical outcomes after transplantation.

\begin{tabular}{|c|c|c|c|c|c|c|c|c|c|c|c|}
\hline UPN & $\begin{array}{c}\text { Sex/Age } \\
\text { (years) }\end{array}$ & Diagnosis & $\begin{array}{l}\text { Donor-recipient } \\
\text { relationship } \\
\text { status }\end{array}$ & $\begin{array}{l}\text { HLA } \\
\text { match }\end{array}$ & $\begin{array}{l}\mathrm{ABO} \\
\text { match }\end{array}$ & $\begin{array}{l}\text { Source of } \\
\text { stem cells }\end{array}$ & $\begin{array}{c}\mathrm{CD}^{+} 4^{+} \\
\text {cells } \\
\left(\times 10^{6} / \mathrm{kg}\right)\end{array}$ & $\begin{array}{c}\text { Case of } \\
\text { DLI }\end{array}$ & $\begin{array}{l}\text { Case of } \\
\text { relapse }\end{array}$ & $\begin{array}{l}\text { Status at last } \\
\text { follow-up }\end{array}$ & Outcome \\
\hline 1 & $\mathrm{M} / 23$ & ALL & Related & Yes & Major & $\mathrm{BM}$ & 4.26 & Yes & Yes & MC & Expired \\
\hline 2 & $M / 45$ & CML & Related & Yes & Minor & BM & 2.30 & No & Yes & $\mathrm{CC}$ & Alive \\
\hline 3 & $M / 34$ & AML & Related & Yes & Major & PBSC & 6.00 & No & Yes & MC & Expired \\
\hline 4 & $F / 33$ & AML & Related & Yes & Major & $\mathrm{BM}$ & 7.45 & No & No & $\mathrm{CC}$ & Alive \\
\hline 5 & $M / 31$ & AML & Related & Yes & Match & PBSC & 7.38 & Yes & Yes & MC & Expired \\
\hline 6 & $M / 31$ & $\mathrm{CML}$ & Related & Yes & Minor & PBSC & 7.58 & No & No & $\mathrm{CC}$ & Alive \\
\hline 7 & $\mathrm{M} / 18$ & $\mathrm{CML}$ & Unrelated & Yes & Major & PBSC & 2.06 & Yes & Yes & Relapse & Expired \\
\hline 8 & $F / 33$ & AML & Unrelated & Yes & Major & $\mathrm{BM}$ & 0.84 & No & No & $\mathrm{CC}$ & Alive \\
\hline 9 & $\mathrm{~F} / 50$ & SAA & Related & Yes & Match & PBSC & 4.37 & No & No & $\mathrm{CC}$ & Alive \\
\hline 10 & $M / 33$ & MDS & Unrelated & Yes & Minor & BM & 0.84 & No & Yes & Relapse & Expired \\
\hline 11 & $F / 29$ & SAA & Related & Yes & Minor & PBSC & 3.40 & Yes & Yes & $\mathrm{CC}$ & Alive \\
\hline 12 & $\mathrm{M} / 44$ & AML & Related & Yes & Minor & PBSC & 4.71 & No & No & $\mathrm{CC}$ & Alive \\
\hline 13 & $F / 36$ & AML & Related & Yes & Minor & PBSC & 6.61 & No & No & $\mathrm{CC}$ & Alive \\
\hline 14 & $F / 56$ & MDS & Related & Yes & Minor & PBSC & 3.50 & No & No & $\mathrm{CC}$ & Expired \\
\hline 15 & $\mathrm{M} / 20$ & AML & Unrelated & $\begin{array}{l}\text { One }(\mathrm{Cw}) \\
\text { mismatch }\end{array}$ & Minor & $\mathrm{BM}$ & 3.02 & No & No & $\mathrm{CC}$ & Expired \\
\hline 16 & $\mathrm{M} / 19$ & ALL & Related & Yes & Minor & PBSC & 7.20 & No & No & $\mathrm{CC}$ & Alive \\
\hline 17 & $\mathrm{M} / 45$ & SAA & Related & Yes & Major & PBSC & 1.50 & No & Yes & $\mathrm{CC}$ & Alive \\
\hline 18 & $\mathrm{~F} / 15$ & AML & Unrelated & Yes & Minor & $\mathrm{BM}$ & 1.95 & No & No & $\mathrm{CC}$ & Alive \\
\hline 19 & $M / 47$ & MDS & Related & Yes & Major & PBSC & 5.32 & No & No & $\mathrm{CC}$ & Expired \\
\hline 20 & $\mathrm{~F} / 41$ & MDS & Related & Yes & Minor & PBSC & 0.16 & No & No & $\mathrm{CC}$ & Alive \\
\hline 21 & $\mathrm{~F} / 43$ & AML & Related & Yes & Major & PBSC & 4.00 & No & No & $\mathrm{CC}$ & Alive \\
\hline 22 & $M / 49$ & AML & Related & Yes & Match & PBSC & 7.85 & No & No & $\mathrm{CC}$ & Alive \\
\hline 23 & $F / 37$ & $\mathrm{PNH}$ & Related & Yes & Match & PBSC & 3.10 & No & No & $\mathrm{CC}$ & Alive \\
\hline 24 & $M / 37$ & MDS & Unrelated & Yes & Match & BM & 2.76 & No & No & $\mathrm{CC}$ & Alive \\
\hline
\end{tabular}

Abbreviations: UPN, unique patient number; $\mathrm{CD} 34^{+}$, positive selection of CD34 cells; DLI, donor leukocyte infusion; $\mathrm{M}$, male; $\mathrm{BM}$, bone marrow; MC, mixed chimerism; CC, complete chimerism; PBSC, peripheral blood stem cell; F, female; SAA, severe aplastic anemia; MDS, myelodysplastic syndrome; $\mathrm{PNH}$, paroxysmal nocturnal hemoglobinuria. 
centages of donor and recipient DNA were calculated from each pair of informative STR markers on the basis of individual proportions of donor (D) and recipient (R) peak areas in relation to the summation of all signals, for example, recipient's DNA $(\%)=(\mathrm{R} 1+\mathrm{R} 2) /(\mathrm{D} 1+\mathrm{D} 2+\mathrm{R} 1+\mathrm{R} 2) \times 100$.

\section{Definition of $M C$}

CC was defined as the presence of $>95 \%$ donor-type hematopoietic cells after allo-SCT. Patients with CC at a certain time point after transplantation can develop a state of MC. MC is defined as the presence of 5-95\% donor-type hematopoietic cells. Split chimerism was defined as CC in one cell type and the presence of recipient-derived cells (totally or in-part) in others.

\section{Statistical analysis}

All statistical analyses were conducted using the SPSS 12.0 statistical package for Windows (SPSS; Chicago, IL, USA). A $P$-value of $<0.05$ was considered to be statically significant.

\section{RESULTS}

\section{Clinical outcome of patients}

The characteristics and clinical data of 24 patients are presented in Table 1. Allo-SCT was performed with a median

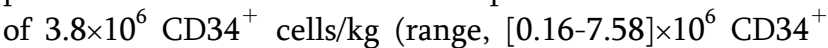
cells $/ \mathrm{kg}$ ). The median follow-up period after transplantation was 19 months (range, 1-59 months). The median periods required for recovering the absolute counts of neutrophils $(>500 / \mu \mathrm{L})$ and platelets $(>20,000 / \mu \mathrm{L})$ were 16 days (range, 11-40 days) and 25 days (range, 17-60 days), respectively. The number of informative STR markers in donor-recipient pairs ranged from 4 to 15 (median, 9). The markers were from a set of 16 polymorphic loci, including D18S51, D8S1179, D16S539, D2S1338 and FGA, which were the most informative loci, and the loci were amplified in 16 or 17 donor-recipient pairs.

\section{Chimerism analysis of patients}

Among the 24 patients, 23 achieved engraftment and only 1 patient (unique patient number [UPN] 7) did not. Twentytwo patients achieved CC in NCs after a median of 23 days

Table 2. Chimerism analysis of relapsed time after transplantation.

\begin{tabular}{lcccc}
\hline & $\begin{array}{c}\text { Relapsed } \\
\text { time (days) } \\
\text { after transplant }\end{array}$ & $\begin{array}{c}\text { Recipient- } \\
\text { derived } \\
\text { NCs (\%) }\end{array}$ & $\begin{array}{c}\text { Recipient- } \\
\text { derived } \\
\text { T cells (\%) }\end{array}$ & $\begin{array}{c}\text { Recipient- } \\
\text { derived } \\
\text { NK cells (\%) }\end{array}$ \\
\hline UPN 3 & 553 & 64.8 & 0.0 & 100.0 \\
UPN 7 & 29 & 100.0 & 100.0 & 100.0 \\
UPN 10 & 64 & 15.4 & NA & 100.0 \\
\hline
\end{tabular}

Abbreviations: NCs, nucleated cells; NK cells, natural killer cells; UPN, unique patient number; NA, not applicable. (range, 12-39 days), and 1 patient (UPN 17) achieved CC after 103 days. One patient (UPN 2) underwent transplantation before the assessment of chimerism by multiplex STR-PCR. NC chimerism was analyzed more than 4 times in all patients (except UPN 2), and the results in $\mathrm{T}$ cells and NK cells during the early engraftment period $(\leq 30$ days after transplantation) could not be confirmed because of low cell numbers.

1) Correlation between chimerism status and relapse

Nine, 6, and 5 patients had 100\% recipient-derived NCs, $\mathrm{T}$ cells, and NK cells or MC in these cells, respectively. Among these 9, 6, and 5 patients, relapse occurred in 8, 3 , and 3 patients, respectively. Further, 3 patients (UPNs 3,7 , and 10) with relapse had $100 \%$ recipient-derived NK cells; NCs and T cells comprised various percentages of recipient-derived cells (Table 2). Patients with relapse had MC or $100 \%$ recipient-derived cells in a part cell type and/or all cell types. In two patients (UPNs 5 and 11), MC in NCs was detected after relapse was clinically diagnosed. $\mathrm{MC}$ in NCs $(P=0.000)$, but not in T cells and NK cells $(P>0.05)$, was significantly correlated with disease relapse (Table 3 ).

2) Correlation between chimerism status and mortality Among the 24 patients, 8 died between days 80 and 571 (median, 307 days). Five patients died because of a relapse or progressive disease (AML, 2; CML, 1; ALL, 1; and myelodysplastic syndrome [MDS], 1) and 3 patients died because of transplant-related complications such as pneumonia. These dead patients included 6 out of the 9 patients with MC in NCs or $100 \%$ recipient-derived NCs $(P=0.007)$.

Patients (4/6) with MC in T cells or $100 \%$ recipient-derived $\mathrm{T}$ cells $(P=0.046)$ and $4 / 5$ patients with $\mathrm{MC}$ in NK cells or $100 \%$ recipient-derived NK cells $(P=0.013)$ died. The results of all lineage-specific chimerism analyses were significantly correlated with mortality (Table 3). Of the 8 relapsed patients who had MC in NCs or $100 \%$ recipient-derived NCs, 4 received donor lymphocyte infusion (DLI) at a median of 252 days (range, 104-457 days); among

Table 3. Correlation between the lineage-specific mixed $/ 100 \%$ recipient chimerism and clinical outcome.

\begin{tabular}{lccc} 
& NCs & T cells & NK cells \\
\hline Number of relapses & $8 / 9$ & $3 / 6$ & $3 / 5$ \\
$P$-value & 0.000 & $\mathrm{NS}$ & $\mathrm{NS}$ \\
Number of mortalities & $6 / 9$ & $4 / 6$ & $4 / 5$ \\
$P$-value & 0.007 & 0.046 & 0.013 \\
Number of occurrences & $4 / 9$ & $2 / 9$ & $2 / 9$ \\
$\quad$ of acute GVHD & $\mathrm{NS}$ & $\mathrm{NS}$ & $\mathrm{NS}$ \\
$P$-value & $6 / 10$ & $3 / 10$ & $1 / 10$ \\
$\begin{array}{l}\text { Number of occurrences } \\
\text { of chronic GVHD }\end{array}$ & $\mathrm{NS}$ & $\mathrm{NS}$ & $\mathrm{NS}$ \\
$P$-value & &
\end{tabular}

The Pearson chi-square test was used to analyze the relationship of donor-type chimerism with relapse and mortality after allogeneic stem cell transplantation.

Abbreviations: NCs, nucleated cells; NK cells, natural killer cells; GVHD, graft-versus-host disease; NS, not significant. 


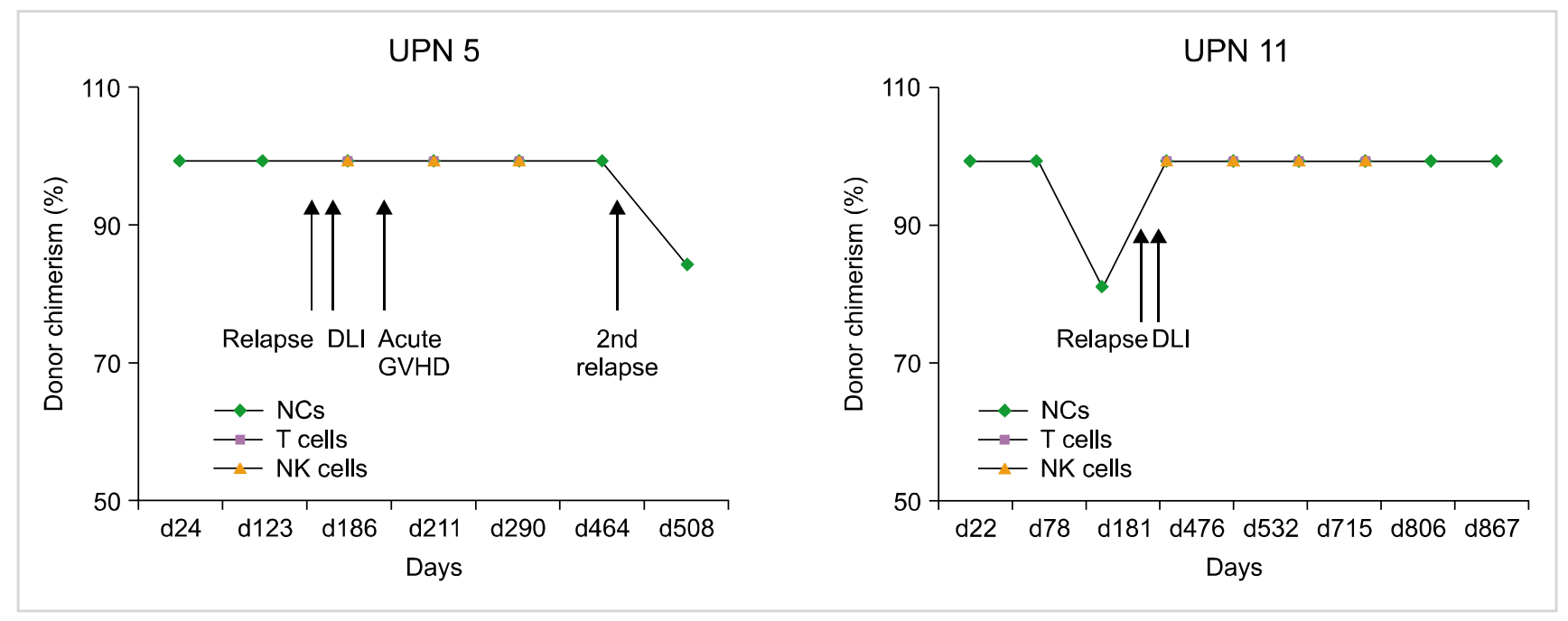

Fig. 1. Chimerism results of unique patient number (UPN) 5 and UPN 11 after donor lymphocyte infusion (DLI). Four patients who received DLI (excluding UPN 11) showed mixed chimerism or relapse. UPN 11 maintained 100\% donor chimerism during 867 days. UPN 5 had acute graft-versus-host disease after DLI. Abbreviations: DLI, donor lymphocyte infusion; GVHD, graft-versus-host disease; NCs, nucleated cells; NK, natural killer.

Table 4. Results of lineage-specific chimerism analysis of UPN 19.

\begin{tabular}{cccc}
$\begin{array}{c}\text { Time (days) } \\
\text { after transplant }\end{array}$ & $\begin{array}{c}\text { Recipient- } \\
\text { derived } \\
\text { NCs (\%) }\end{array}$ & $\begin{array}{c}\text { Recipient- } \\
\text { derived } \\
\text { T cells (\%) }\end{array}$ & $\begin{array}{c}\text { Recipient- } \\
\text { derived } \\
\text { NK cells (\%) }\end{array}$ \\
\hline 14 & 0.0 & NA & NA \\
32 & 7.2 & 29.0 & 0.0 \\
93 & 0.0 & 19.5 & 0.0 \\
105 & 0.0 & 0.0 & 0.0 \\
119 & 0.0 & 18.5 & 0.0 \\
162 & 0.0 & 0.0 & 0.0 \\
274 & 0.0 & 0.0 & 0.0 \\
\hline
\end{tabular}

Abbreviations: NCs, nucleated cells; NK cells, natural killer cells; NA, not applicable.

these, 1 patient (UPN 11) maintained complete remission during 867 days and 3 patients (UPNs, 1, 5, and 7) died because of secondary relapse (Fig. 1).

3) Correlation between chimerism status and acute/chronic GVHD

Of the total of 24 patients, 9 (37.5\%) developed acute GVHD, and 3 of them developed the condition after DLI. Of the 9 patients with acute GVHD, 4, 2, and 2 patients had $100 \%$ recipient-derived NCs, T cells, and NK cells or $\mathrm{MC}$ in these cells, respectively. MC in all cell types was not significantly correlated with the incidence of acute GVHD $(P>0.05)$. Of the 24 patients, $10(41.6 \%)$ had extensive chronic GVHD. Among these patients, 6, 3, and 1 patients had 100\% recipient-derived NCs, T cells, and NK cells or MC in these cells, respectively. Six patients had MC in T cells, and 3 of them had chronic GVHD. In UPN 19 , $\mathrm{T}$ cells consisted of $29.0 \%, 19.5 \%$, and $18.5 \%$ recipient cells on days 32, 93, and 119, respectively, and chronic GVHD was observed continuously from days 130 to 220 (Table 4). UPNs 3 and 6 had MC in T cells around the onset of chronic
GVHD. Two patients (UPNs 7 and 10) with MC in T cells had acute GVHD. Another patient (UPN 24) did not have acute/chronic GVHD. Four of the 10 patients with chronic GVHD showed CC in all cell types. MC in all cell types was not correlated with the incidence of acute and chronic GVHD ( $P>0.05$; Table 3$)$.

\section{DISCUSSION}

Chimerism analyses are routinely performed to monitor engraftment [1-4]. The persistence or reappearance of autologous cells has often been observed after SCT. Several studies performed during the last 20 years have reported that MC is associated with graft rejection [11, 16-20]. Chimerism analysis is still controversial because some studies did not find a correlation between chimerism and disease relapse [21, 22].

In this study, we analyzed the chimerism status of NCs, $\mathrm{T}$ cells, and NK cells from myeloablative allo-SCT patients by using multiplex STR-PCR and determined the correlation between these results and the clinical outcome. We found that among the patients observed, 9 had MC in NCs or $100 \%$ recipient-derived NCs, and the disease relapsed in all the patients, except UPN 19. In 2 patients, MC in NCs was detected after the clinical diagnosis of relapse. This may be explained by the long intervals between chimerism analysis and SCT, which increase the risk of overlooking a rapidly evolving MC before hematological relapse. MC in NCs was significantly correlated with disease relapse. Five patients had MC in NK cells or $100 \%$ recipient-derived NK cells, and 3 of these patients had $100 \%$ recipient-derived NK cells. NCs and T cells comprised recipient-derived cells in various proportions. NK cells were not significantly correlated with relapse despite $\mathrm{MC}$ in NK cells in patients with disease relapse. Baron et al. [17] found that in patients who had 
undergone non-myeloablative SCT, low donor T-cell and NK-cell chimerism levels on day 14 were associated with high probabilities of graft rejection and that an early establishment of donor NK-cell chimerism was associated with better progression-free survival. We found that the chimerism status differed among different cell lineages in 6 patients with myeloid malignancies (UPNs 3, 6, 10, 15, 19, and 24). Four out of the 6 cases were published previously [23]. Zeiser et al. [18] reported that conventional chimerism analysis had lower sensitivity $(<3 \%)$ than lineage-specific chimerism analysis $(0.1 \%)$. Patients with MC in NK cells or $100 \%$ recipient-derived NK cells were diagnosed with AML or MDS. One patient (UPN 15) with AML had 54.5\% blasts in the $\mathrm{BM}$ and no blasts in the PB. Few studies have reported relapse in the $\mathrm{BM}$ without prior detection of recipient cells in the PB [24]. Myeloblasts were not CD56-positive at the time of diagnosis in any of the cases. However, we could not totally exclude the possibility that the blasts expressed low levels of CD56 from the onset or acquired the ectopic marker during treatment or relapse. The data supported the concept that persistence of MC in NK cells in patients with AML and MDS reduces the graft-versus-malignancy (GVM) effect and helps to promote relapse. Clausen et al. [25] found that a grafted NK cell dose was associated with a lower risk of relapse and improved survival.

We confirmed that the presence of $100 \%$ recipient-derived NCs, T cells, and NK cells or MC in these cells was correlated with mortality. This observation indicated the importance of short interval chimerism analysis; immediate therapeutic intervention is needed if an increase in the level of MC is noted. The role of DLI in patients with relapse is unclear $[18,26]$. In this study, 4 patients with $\mathrm{MC}$ and relapse received DLI, and all, except UPN 11, had secondary relapse. In the present study, patients who had developed increased MC and, therefore, received additional DLI did not have enhanced GVM effect, and autologous hematopoiesis could not be eliminated. McSweeney et al. [27] recommended consider DLI for declining donor chimerism, but a higher than $20 \%$ of donor $\mathrm{T}$ cells chimerism, stable MC of $>2$ weeks, or progressive disease. Further evidence of reduced alloreactivity in patients with MC is provided by a lower incidence of severe acute GVHD and a higher incidence of relapse in patients with MC after SCT than in patients with CC [28, 29]. Michallet et al. [28] showed a significant correlation between chimerism status and overall survival as well as between chimerism status and the incidences of acute and chronic GVHD. Mattsson et al. [29] reported that about $82 \%$ of patients had MC for donor/host T cells at the onset of acute GVHD. In this study, MC in all cell types was not correlated with the incidence of acute and chronic GVHD. However, 6 patients showed MC in T cells, and 3 (UPNs 3, 6, 19) of these patients had chronic GVHD. UPNs 7 and 10 with MC in T cells had acute GVHD. Although no clear conclusion could be made because of the lack of statistically significant correlation, $\mathrm{MC}$ in $\mathrm{T}$ cells may influence GVHD.

In the case of high-risk patients or when other suitable disease markers are not available, sequential chimerism analysis in leukocyte subsets permits early detection of relapse and facilitates the monitoring of therapeutic interventions. Furthermore, prospective clinical studies should include large numbers of patients with the same disease. Despite the above-mentioned drawbacks; we believe that these chimerism data could be used as the fundamental basis for monitoring the outcome of myeloablative SCT, which is commonly performed in Korea.

\section{REFERENCES}

1. Lion T. Detection of impending graft rejection and relapse by lineage-specific chimerism analysis. Methods Mol Med 2007;134: 197-216.

2. Bader P, Kreyenberg H. Analysis of chimerism after stem cell transplantation. Methods Mol Med 2004;91:247-64.

3. Liesveld JL, Rothberg PG. Mixed chimerism in SCT: conflict or peaceful coexistence? Bone Marrow Transplant 2008;42:297-310.

4. Khan F, Agarwal A, Agrawal S. Significance of chimerism in hematopoietic stem cell transplantation: new variations on an old theme. Bone Marrow Transplant 2004;34:1-12.

5. Gineikiene E, Stoskus M, Griskevicius L. Recent advances in quantitative chimerism analysis. Expert Rev Mol Diagn 2009;9: 817-32.

6. Bornhäuser M, Oelschlaegel U, Platzbecker U, et al. Monitoring of donor chimerism in sorted $\mathrm{CD} 34^{+}$peripheral blood cells allows the sensitive detection of imminent relapse after allogeneic stem cell transplantation. Haematologica 2009;94:1613-7.

7. Kristt D, Stein J, Yaniv I, Klein T. Assessing quantitative chimerism longitudinally: technical considerations, clinical applications and routine feasibility. Bone Marrow Transplant 2007;39:255-68.

8. Bader P, Niethammer D, Willasch A, Kreyenberg H, Klingebiel $\mathrm{T}$. How and when should we monitor chimerism after allogeneic stem cell transplantation? Bone Marrow Transplant 2005;35:10719.

9. Ma X, Wu D, Sun A, et al. The value of monitoring minimal residual disease in the patients with donor lymphocyte infusion as intervention of relapsed/refractory acute lymphoblastic leukemia after allogeneic hematopoietic stem cell transplantation. Am J Hematol 2010;85:141-2.

10. Dey BR, Shaffer J, Yee AJ, et al. Comparison of outcomes after transplantation of peripheral blood stem cells versus bone marrow following an identical nonmyeloablative conditioning regimen. Bone Marrow Transplant 2007;40:19-27.

11. Baron F, Sandmaier BM. Chimerism and outcomes after allogeneic hematopoietic cell transplantation following nonmyeloablative conditioning. Leukemia 2006;20:1690-700.

12. Dey BR, McAfee S, Colby C, et al. Impact of prophylactic donor leukocyte infusions on mixed chimerism, graft-versus-host disease, and antitumor response in patients with advanced hematologic malignancies treated with nonmyeloablative conditioning and allogeneic bone marrow transplantation. Biol Blood Marrow Transplant 2003;9:320-9.

13. Kristt D, Israeli M, Narinski R, et al. Hematopoietic chimerism monitoring based on STRs: quantitative platform performance on 
sequential samples. J Biomol Tech 2005;16:380-91.

14. Thiede C. Diagnostic chimerism analysis after allogeneic stem cell transplantation: new methods and markers. Am J Pharmacogenomics 2004;4:177-87.

15. Lobashevsky AL, Senkbeil RW, Townsend JE, Mink CA, Thomas JM. Quantitative analysis of chimerism using a short tandem repeat method on a fluorescent automated DNA sequencer. Clin Lab Haematol 2006;28:40-9.

16. Horn B, Soni S, Khan S, et al. Feasibility study of preemptive withdrawal of immunosuppression based on chimerism testing in children undergoing myeloablative allogeneic transplantation for hematologic malignancies. Bone Marrow Transplant 2009;43: 469-76.

17. Baron F, Baker JE, Storb R, et al. Kinetics of engraftment in patients with hematologic malignancies given allogeneic hematopoietic cell transplantation after nonmyeloablative conditioning. Blood 2004;104:2254-62.

18. Zeiser R, Spyridonidis A, Wäsch R, et al. Evaluation of immunomodulatory treatment based on conventional and lineage-specific chimerism analysis in patients with myeloid malignancies after myeloablative allogeneic hematopoietic cell transplantation. Leukemia 2005;19:814-21.

19. Huisman C, de Weger RA, de Vries L, Tilanus MG, Verdonck LF. Chimerism analysis within 6 months of allogeneic stem cell transplantation predicts relapse in acute myeloid leukemia. Bone Marrow Transplant 2007;39:285-91.

20. Fernández-Avilés F, Urbano-Ispizua A, Aymerich M, et al. Serial quantification of lymphoid and myeloid mixed chimerism using multiplex PCR amplification of short tandem repeat-markers predicts graft rejection and relapse, respectively, after allogeneic transplantation of CD34 $4^{+}$selected cells from peripheral blood. Leukemia 2003;17:613-20.

21. Schaap N, Schattenberg A, Mensink E, et al. Long-term follow-up of persisting mixed chimerism after partially $\mathrm{T}$ cell-depleted allo- geneic stem cell transplantation. Leukemia 2002;16:13-21.

22. Choi SJ, Lee KH, Lee JH, et al. Prognostic value of hematopoietic chimerism in patients with acute leukemia after allogeneic bone marrow transplantation: a prospective study. Bone Marrow Transplant 2000;26:327-32.

23. Goh RY, Cho SS, Song YJ, et al. Clinical utility of chimerism status assessed by lineage-specific short tandem repeat analysis: experience from four cases of allogeneic stem cell transplantation. Korean J Lab Med 2009;29:277-81.

24. Lion T, Daxberger H, Dubovsky J, et al. Analysis of chimerism within specific leukocyte subsets for detection of residual or recurrent leukemia in pediatric patients after allogeneic stem cell transplantation. Leukemia 2001;15:307-10.

25. Clausen J, Kircher B, Auberger J, et al. The role of missing killer cell immunoglobulin-like receptor ligands in T cell replete peripheral blood stem cell transplantation from HLA-identical siblings. Biol Blood Marrow Transplant 2010;16:273-80.

26. Campregher PV, Gooley T, Scott BL, et al. Results of donor lymphocyte infusions for relapsed myelodysplastic syndrome after hematopoietic cell transplantation. Bone Marrow Transplant 2007;40:965-71.

27. McSweeney PA, Niederwieser D, Shizuru JA, et al. Hematopoietic cell transplantation in older patients with hematologic malignancies: replacing high-dose cytotoxic therapy with graft-versus-tumor effects. Blood 2001;97:3390-400.

28. Michallet AS, Fürst S, Le QH, et al. Impact of chimaerism analysis and kinetics on allogeneic haematopoietic stem cell transplantation outcome after conventional and reduced-intensity conditioning regimens. Br J Haematol 2005;128:676-89.

29. Mattsson J, Uzunel M, Brune M, et al. Mixed chimaerism is common at the time of acute graft-versus-host disease and disease response in patients receiving non-myeloablative conditioning and allogeneic stem cell transplantation. Br J Haematol 2001;115:935-44. 